\title{
PRÁTICAS DE LETRAMENTOS NA EDUCACุÃO DO CAMPO: O PROGRAMA ESCOLA DA TERRA EM ALAGOAS
}

\author{
Sanadia Gama dos Santos ${ }^{1}$ \\ Mariléia Silva dos Reis ${ }^{2}$
}

\begin{abstract}
Resumo: O projeto Escola da Terra, desenvolvido pela Universidade Federal de Alagoas de 2015 a 2017, oferta cursos de aperfeiçoamento para professores das séries multisseriadas e quilombolas da rede estadual e municipal de Alagoas. Neste artigo, tratamos da reflexão sobre o modo como foi articulada a formação em Língua Portuguesa, no eixo "Linguagens e práticas de letramento na Educação do campo" do referido Programa. Reconhecemos a importância de o professor valorizar os vínculos com a terra e fomentar a reprodução sociocultural de diferentes áreas do conhecimento. O recorte teórico aborda os letramentos sociais propostos por Street (2014), que define o conceito de letramento ideológico como parte integrante da cultura e por Achard (1989), que traz o conceito de língua como um elemento político, interdisciplinar e identitário. Visualizamos a importância do Programa como uma política de fortalecimento social no campo para a superação dos processos de afirmação dos sujeitos na escola, bem como na comunidade local.
\end{abstract}

Palavras-chave: Educação do campo. Letramentos. Cultura e sociedade.

\section{PRACTICES OF LITERACY IN FIELD EDUCATION: THE PROGRAM ESCOLA DA TERRA IN ALAGOAS}

\begin{abstract}
The Escola da Terra project, developed by the Federal University of Alagoas since 2015 has offered training courses for teachers on multi-series and quilombolas schools from the public education of Alagoas. In this article, we deal with the reflection on how the Portuguese language training has been articulated in the "Language and literacy practices in rural education" through that project. We recognize the importance of teachers to value the ties with the land and to foment the socio-cultural reproduction of different areas of knowledge. The theoretical section addresses the social literacy proposed by Street (2014), who defines the concept of ideological literacy as an integral part of culture, and by Achard (1989), who brings the concept of language as a political, interdisciplinary and identity element. We see the importance of that Program as a social empowerment policy in the field to overcome the processes of affirmation of the subjects in the school, as well as in the local community.
\end{abstract}

Keywords: Rural education. Literacies. Culture and society.

\footnotetext{
${ }^{1}$ Mestre em Letras pela Universidade Federal de Sergipe. Doutoranda em estudos linguísticos pela Universidade Estadual de Maringá. Professora Auxiliar da Universidade Estadual de Alagoas. Email: sanadiasantos@yahoo.com.br.

${ }^{2}$ Doutora em Letras pela Universidade Federal de Santa Catarina. Professora adjunta da Universidade Federal em Sergipe. Email: prof.marileia.ufs@gmail.com.
} 


\section{Introdução}

Este artigo apresenta uma reflexão acerca da formação de professores de Língua Portuguesa, no eixo "Linguagens e práticas de letramento na Educação do Campo", em Escola da Terra, projeto que visa contribuir para a oferta de uma educação campesina contextualizada às realidades das suas populações, de qualidade e de conformidade com as Diretrizes Curriculares para as Escolas do Campo. Em Alagoas, trata-se da ampliação do acesso à formação continuada, no nível de aperfeiçoamento, de professores das redes municipal e estadual que atuam nas classes quilombolas e multisseriadas do 1 음 ao 5 ㅇ ano do Ensino Fundamental das Escolas do Campo, de todo o Estado, desde 2015.

Escola da Terra resulta da parceria entre a Universidade Federal de Alagoas (UFAL), vinculada à Pró-reitoria de Extensão, e a Coordenação Geral de Políticas de Educação do campo (CGPEC), vinculada à Secretaria de Educação Continuada Alfabetização, Diversidade e Inclusão (Secadi/MEC), segundo Pepe et all (2016), coordenadora institucional do Comitê Gestor Institucional de Formação Inicial e Continuada de Profissionais do Magistério da Educação Básica (Comfor) ${ }^{3}$.

A formação do profissional do campo está alicerçada na pedagogia histórico-crítica, em que se firmam melhorias na prática pedagógica, na qualificação docente e nas condições de acesso, permanência e aprendizagem dos estudantes do campo e de quilombos e em suas comunidades. Para a coordenadora, “aborda-se a Educação do campo e quilombola a partir da perspectiva do território, entendendo que este é muito mais do que chão, com base no conceito de Milton Santos, de que território é a soma de terra mais as relações sociais" (PEPE et all, 2016).

Hoje, ainda é um grande desafio para os professores atuar em salas multisseriadas, visto que costumam ser preparados profissionalmente para o sistema escolar regular. Então, estar em uma sala com diferentes níveis escolares, com crianças com idade e nível escolar diverso, é, de fato, muito complexo. Uma outra dificuldade refere-se ao fato de a maioria dos

\footnotetext{
${ }^{3}$ Equipe gestora do projeto Escola da Terra na UFAL: Professora Doutora Cristiane Marcela Pepe (Coordenação Geral); Professora Mestra Ana Cláudia Laurindo de Oliveira (Supervisora); Professor Mestre Reinaldo Sousa (Professor Pesquisador); Professor Especialista Valdeck Gomes (Coordenador Estadual); Formadores: Professora Mestra Claudia Maria de Lima; Professora Mestra Gleica Martins e Professora Mestra Sanádia Gama dos Santos; Deividy Clécio Barros (Secretário Administrativo).
} 
professores, além de residir no espaço urbano, desenvolvem suas atividades sociais também neste espaço. E, assim, chega a ser um "choque entre a formação que recebem e o que necessitam para atuar na prática, além de ter que pensar isso na especificidade do campo", esclarece a coordenação na UFAL, acrescentando que os cursos de formação funcionam com base na “alternância pedagógica entre tempo universidade e tempo comunidade, com seis módulos de formação, que abordam de alfabetização e letramento à economia solidária".

A base formadora, discursiva e prático-metodológica dos encontros é firmada nesses eixos, sendo "Linguagens e práticas de letramento na Educação do campo" o objeto de reflexão sobre o qual o presente artigo trata. São eles:

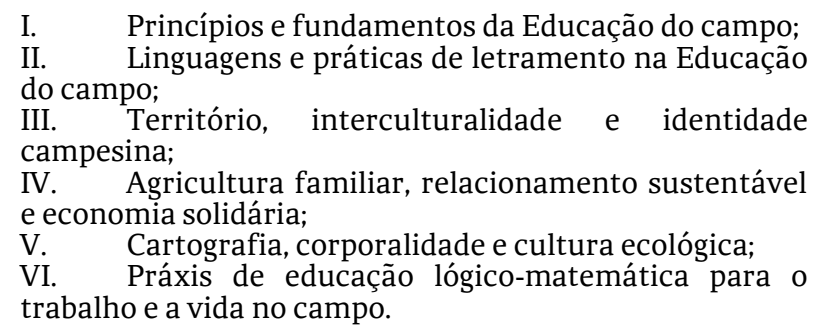

Esses eixos foram pensados e refletidos pela equipe de formadoras do programa das diversas áreas do conhecimento: letras, sociologia, ciências da natureza que juntas pensam uma proposta coletiva de atividades para cada grupo de professores que estão participando dos cursos. Para o eixo 2, letramento e educação do campo, o trabalho visava à autoafirmação dos sujeitos em todas as condições sociais de convivência e interação, com respeito a questões identitárias do campo, incluindo as diferenças linguísticas.

Nesses termos, nosso objetivo consiste em descrever o modo como foi articulado o ensino de Língua Portuguesa nas formações, com vistas a um leitor campesino crítico e fluente, que compreenda os textos que circulam nas variadas esferas sociais. Este propósito se firma à estrutura do projeto Escola da Terra como estratégias de ensino e de aprendizagem que visam a uma educação integral e integrada, mediante a articulação da escola (criança, professores e funcionários), da família e da comunidade rural, tendo em vista a primazia por uma educação que situa a criança num todo harmônico (cognição, afetividade, ética e cor local) e que integra as disciplinas 
constituintes dos eixos acima descritos, observando sempre o respeito à variedade sociolinguística usada pelos alunos no momento da leitura e das interações orais.

\section{A língua como elemento de identidade cultural e social}

A concepção de língua por meio de uma abordagem sociocultural e transdisciplinar, proposta por César e Cavalcanti (2007), defende a necessidade de enfrentarmos os dilemas no trabalho pedagógico com a linguagem nos diferentes contextos em que a língua é usada, a partir das regras articuladas por cada grupo. Nesse sentido, remonta-se a uma releitura crítica do conceito a partir das categorias, como dialeto, variedade, multilinguismo, que estão dentro do campo da Linguística Aplicada, tendo como base os estudos sobre escola/escolarização em contextos socioculturais e sobre as chamadas "minorias linguísticas" por afirmação identitária e autonomia política.

Achard (1989) afirma ser a língua um contorno basicamente político, um elemento que leva à história da colonização da língua, apoiando-se num caráter totalizante e único, o que hegemoniza a língua como critério de identidade. Neste trabalho, nossa abordagem da língua parte de um contexto sociocultural para compreender os povos marginalizados e os processos vividos historicamente mediante colonização da língua e expansão dela em vários países. A língua passa, então, a um elemento cultural, interdisciplinar e identitário e está dentro dos estudos que ampliam as possibilidades de inclusão das minorias dentro das instituições de poder, como a escola e suas práticas pedagógicas a partir do respeito aos modos de uso da língua dos deferentes povos do campo.

Para Moita Lopes (1996), a respeito dessa visão interdisciplinar da Linguística Aplicada "o linguista aplicado, partindo de um problema com o qual as pessoas se deparam ao usar a linguagem na prática social e em um contexto de ação, procura subsídios em várias disciplinas que possam iluminar teoricamente a questão em jogo, ou seja, que possam ajudar a esclarecê-la" (1996, p. 114). Essa postura politizada do estudo da língua sustenta-se pela valorização das alteridades se das identidades marginalizadas de acordo com diversas abordagens sociológicas e antropológicas, que buscam 
alternativas para dar visibilidade à língua dos povos quilombolas e indígenas, por exemplo. Essa visão social e política, conforme Mignolo (2008), fortalece uma opção descolonial, que busca se desvincular dos conceitos europeus e tradicionais herdados para as ciências.

Nesse sentido, ao fazer a opção epistêmica de identidade em política, damos lugar às vozes dos grupos sociais marginalizados, por adotarmos para a linguagem esse lugar de escolha representacional dos marginalizados, sobretudo os povos do campo, que sofrem historicamente a invisibilidade e a marginalização social, bem como suas práticas de linguagem que acontecem no cotidiano de suas vidas, por meio do trabalho de campo, numa opção interdisciplinar, que tanto é sustentada pelas ciências humanas, como pela Linguística Aplicada, Sociolinguística, Dialetologia e ciências afins.

Para os estudos em que o sujeito participa do processo educacional, a construção das diferentes identidades sempre deve ser analisada. Pelas diferentes particularidades dos sujeitos envolvidos com a Educação no Campo, seguimos a perspectiva do hibridismo e das intersecções territoriais. Estamos preocupados com particularidades desses sujeitos, de acordo com a proposta de Rajagopalan (2003), que utiliza o conceito de representação para relativizar as verdades sobre identidade e poder, que deixam de ser exatas. Para esse autor, a noção de linguagem está associada a um conceito de globalização pós-mundial. Na ciência da linguagem, há certos fatores peculiares que tornam um pouco mais delicada a questão da identificação exata do objeto (RAJAGOPALAN, 2003, p. 23).

Ao questionarmos a centralidade da língua padrão, estamos abrindo espaço para novas modalidades da língua, conforme seu uso, pois o trabalho com a Língua Portuguesa na Educação do campo sempre pede o reconhecimento de novas representações dos sujeitos participantes. Tal posicionamento ideológico é sustentado pela tese do representacionalismo e é, ao mesmo tempo, uma questão política e linguística e, nesse caso, a questão política e a questão linguística são uma só, pois, ao falar uma língua, ao nos engajarmos na atividade linguística, estaríamos, todos nós, comprometendonos politicamente e participando de uma atividade eminentemente política, de acordo Rajagopalan (2003, p. 23).

Se concebermos o conceito de língua e linguagem, numa perspectiva crítica, reforçamos a dinâmica dos letramentos que reconhecem tanto a fala quanto a escrita como modalidades de articulação da língua. Assim, 
compreender que, na Educação do campo, sobretudo no ensino de língua nas escolas, os processos de aprendizagem estão acima do ensino, visto que se trata de uma abordagem política que explora o espaço de aprendizagem como inter-relação de saberes e de uma dimensão crítica e dialógica com as práticas e exercícios da vida cotidiana.

Como prática de inclusão, a avaliação social do uso da língua leva em conta tantos as questões dos sujeitos no processo de aprendizagem, conforme Moita Lopes (1993), quanto a questão da representação de Rajagopalan (2003). Leva-se, em conta, portanto, a variação social e diatópica da linguagem.

E, para ilustrarmos esse propósito, foi proposto, em uma das oficinas de formação, que os docentes pesquisassem, onde a comunidade reside, a identificação de expressões e falares mais utilizados pelas pessoas da localidade, a fim de reconhecerem as múltiplas diferenças de fala, no sentido de compreenderem as variações linguísticas da localidade. Tal prática proporcionou atividades em que se puderam observar as variações linguísticas dos alunos campesinos, dos pais e de cada comunidade, conforme Quadro I.

Quadro 1 - Ilustração das falas de comunidades campesinas de Alagoas
\begin{tabular}{|l|l|}
\hline NORMA PADRÃO & FORMAS DE FALAR \\
\hline Armário & Guarda-roupa \\
\hline Caldeirão & Carderão \\
\hline Vômito & Lançar \\
\hline Túmulo & Catatumba \\
\hline Mamadeira & Gogó \\
\hline Jornal & Jornar \\
\hline Sentar & Se abancar \\
\hline Estômago & Estambo \\
\hline
\end{tabular}

As especificidades da forma de falar dessas comunidades reforçam que as regras de uso da língua não se limitam a uma família, ou a particularidade de alguns de seus usurários. Pelo contrário, constatamos que há algumas regras linguísticas mais (e menos) recorrentes entre os falantes. Por exemplo, a articulação da semivogal /w/, representada pela letra “l”, em 
“caldeirão" e "jornal", por exemplo, foram pronunciadas como se fossem escritas pela letra "r", no povoado analisado, o que evidencia certa influência de um português popular, de natureza mais europeizada, trazido da tradição dos mais antigos e que se mantém nas falas dos moradores da região até hoje.

Com base neste breve estudo de campo, foram reforçados os princípios da valorização da diferença e da identificação de normas dentro do próprio falar da região. Além disso, a observação de tais variedades de uso da linguagem na referida comunidade subsidiou também a reflexão sobre as diferenças entre fala e escrita, em que foi reforçado o princípio, segundo o qual não falamos como escrevemos. Os professores compreenderam melhor que, para a fala, o usuário da língua tem autonomia para usá-la de modo mais variável e, assim, firmar a sua identidade, em especial, a diatópica, que é a variedade do seu "topus", da sua topografia. Por outro lado, na escrita, atentamos para os princípios do sistema alfabético, que são únicos, em todo o território nacional.

Nesta perspectiva, Mignolo (2008) esclarece que é fundamental termos uma prática de ensino "descolonial" nas aulas de Língua Portuguesa, em especial, aos participantes da Escola no Campo. Essa mudança de paradigma tem sido fundamental para desconstruirmos a imposição de apenas uma língua padrão como estava presente na compreensão dos participantes no início do módulo. E, em Marcuschi (2008), temos o falante como um sujeito que domina as regras dessa língua. Reforça-se que a língua oral não tem regras tão rígidas quanto imaginamos, pois há muitas variações, quando pensamos no uso de uma língua. Todavia, mais uma vez, foi destacada a função normatizadora da gramática, ao padronizar esses usos e fixar os limites da língua escrita. Se a língua escrita é cercada de normas e regras, a oral é livre, espontânea e aberta às experimentações que cada comunidade vai propondo conforme as necessidades de uso.

\section{A formação de educadores do campo}


Abordar a Educação do campo no Brasil e especificamente em Alagoas remete-nos de imediato a pensar o campesino como sujeito transformador de si e do espaço em que vive. Sabemos que o Estado ainda não conseguiu efetivar respostas satisfatórias ao problema educacional, principalmente em referência ao campo, onde emergem vários desafios. Antes de tudo, faz-se necessário o Estado inverter a lógica de atendimento. Quem são os sujeitos? Quais são as demandas? A lógica atual foca a partir do urbano para o campo, impondo currículos, didáticas, livros que não remetem suas realidades cotidianas, persistindo na negação freireana de uma educação libertadora, de currículo crítico e humanização dos sujeitos, tendo a si e ao seu meio como referenciais para o aprendizado e para a consciência crítica, superando a opressão e o determinismo, sendo o cidadão o próprio construtor do seu conhecimento, a partir do seu contexto sociocultural.

Nesse sentido, a formação de professores, como parte constitutiva da formação humana, no interior das universidades, tem um sentido social relevante, uma vez que possibilita momentos educativos que visam desenvolver atividades teórico-práticas, circunscritas, na ideia central, de ação educativa coletiva para professores de escolas do campo, na perspectiva de materializar o exercício concreto de estudos, e estes serem objetos de sociabilidade, via docência, para a formação geracional de crianças, adolescentes e adultos, nas redes de ensino e além dessas.

A formação do docente exige fundamentação sólida, para se caracterizar como qualificação contextualizada, enquanto aporte para assegurar a permanência e continuidade ao professor e, assim, este poder estender ao seu ofício elementos que recebeu no processo de cursos de formação, reflexão, conteúdos, técnicas, metodologias, como um conjunto de conhecimento sobre diversas áreas, em que pese marcos da História, Sociologia, Antropologia, Psicologia, Geografia, Linguagens, Matemática, Artes, Cultura, Educação, Etnia, Racismo e Consciência Negra, com recorte para interfaces múltiplas com o campo, constituindo, assim, o que denominamos de formação, além de integral, também integrada aos saberes e às ciências diversas.

A concepção de língua para os professores que atuam em escolas multisseriadas traz inúmeras complexidades na concepção de aprendizagem, na politização do currículo e no lugar em que produzimos os conhecimentos pré-estabelecidos na formação das licenciaturas, visto que, para a maioria dos 
professores que atuam no Programa, a formação universitária deles nem sempre é na área de Letras: há também professores formados em outras áreas do conhecimento, mas que lecionam Língua Portuguesa. Então, se, por um lado, para o Programa, é importante essa interdisciplinaridade, por outro, se formos pensar em conhecimento sobre concepção sobre ensino de língua, percebemos que ainda há diversas limitações de ordem cultural, social e de conhecimento sobre a concepção.

Constitui-se de vital importância para o desenvolvimento humano uma concepção de aprendizagem que envolve a dimensionalidade entre as áreas de conhecimento e a realidade social. A formação docente não deve se dar em si mesma e isolada das questões sociais, políticas e econômicas, uma vez que a educação é uma mediação para a transformação social. Neste sentido, a Educação do campo, no contexto do campo, exige compreender as diversas relações sociais, nessas Políticas públicas em que se materializam via Projetos, e que perpassam em nível de campo e extracampo.

\begin{abstract}
Os sujeitos que trabalham e vivem do campo e seus processos de formação pelo trabalho, pela produção de cultura, lutas sociais, não têm encontrado como parâmetros na construção da teoria pedagógica e muitas vezes são tratados de modo preconceituoso, discriminatório. A realidade desses sujeitos não costuma ser considerada quando se projeta um desenho de escola. Esta é a denúncia feita pela especificidade da Educação do campo: o universal tem sido pouco universal, $\mathrm{O}$ que se quer, portanto, não é ficar na particularidade, fragmentar o debate e as lutas; ao contrário, a luta é para que o "universal seja mais universal", seja de fato, síntese das particularidades diversas, contraditórias (CALDART, 2008).
\end{abstract}

Trazer à formação docente compreensões teórico-metodológicas em que se vislumbrem língua e linguagem associadas às questões de identidade e a aspectos socioculturais contribui para uma dimensão relacional e dialógica com o lugar de pertencimento do aprendiz, sua cultura e também contribui para afirmação daquilo que o indivíduo se constitui no seu cotidiano. A representação da cultura local na fala tem em sua natureza uma história e marca nos sujeitos o que ele realmente é em sua essência.

\title{
3. Práticas de letramento na Educação do campo
}

Nesta seção, tratamos de práticas de letramento como práticas sociais situadas, ou seja, práticas sociais de leitura e de escrita presentes no 
cotidiano de toda a sociedade e indivíduos, portanto, nas desenvolvidas em usos sociais corriqueiros, vistas como práticas de leitura e escrita daquilo que está em torno da cultura dos indivíduos e que são necessárias à vida humana.

Percebemos, portanto, que todas as atividades diárias constituem formas de utilização social da leitura e da escrita, constituídas, assim, como práticas de letramento. Neste sentido, Street (2014) apresenta dois conceitos de letramento: o autônomo e o ideológico, que consideram o letramento crítico, no sentido de dar ênfase aos aspectos ideológicos da prática social.

Essa visão ideológica de Street leva ao termo letramentos, no plural e como letramentos múltiplos, os usos sociais de leitura e escrita a que o sujeito fica exposto no seu contexto social.

$\mathrm{Na}$ concepção ideológica de letramentos, Street (2014) considera o letramento sob dois conceitos: o autônomo e o ideológico. Em relação ao modelo autônomo, refere-se, basicamente, às habilidades individuais do sujeito e, no que diz respeito ao modelo ideológico, trata das práticas sociais que envolvem leitura e escrita em geral.

No modelo autônomo, estão incluídas as atividades de processamento da leitura, tanto as que ocorrem de forma consciente quanto as inconscientes, na construção de sentido do texto. Esse processo ideológico do letramento propõe uma prática social, pois as diversas maneiras pelas quais as pessoas usam a leitura e a escrita estão vinculadas às questões de conhecimento, identidade e modos de ser e estar no mundo, seja nas práticas sociais ou em contextos específicos.

Desse modo, os letramentos desses sujeitos estarão dependentes desses contextos e, neles, as relações de poder desempenham um papel predominante. O autor vê as práticas de letramento como indissoluvelmente ligadas às estruturas culturais e de poder da sociedade e reconhece a variedade de práticas culturais associadas à leitura e à escrita em diferentes contextos.

Os letramentos ideológicos estão dentro dos autônomos, na medida em que as características sociais e históricas são o determinante do tempo e do local em que ocorrem, isto é, os letramentos autônomos requerem o contato direto com a escrita e, desse modo, permitem que o aluno se aproprie de níveis, cada vez maiores, de letramento.

Uma das profundas discussões trazidas por Street baseia-se nos modelos de letramento utilizados por cientistas, instituições, políticas 
públicas, professores, mídia, etc, em que ele critica os efeitos cognitivos do letramento na dicotomia entre fala e escrita, numa concepção dominante (STREET, 2014).

Essas concepções têm como modelo de letramento o "autônomo" e são medidas por graus nos sujeitos em relação a sua capacidade de utilização do texto escrito. Essa ideologia é criticada por Street como algo que não leva em consideração as práticas construídas por meio de sua cultura e identidade, mas, sim, com base numa ideia hegemônica que exclui, domina e oprime o sujeito, de modo a reduzir suas práticas de fala e escrita ou de leitura e escrita como medições de um modelo padrão de ascensão social, fator que gera desigualdades sociais e até de classes. Dessa forma, é possível inferir que o conceito de letramento deve considerar os usos da linguagem e as diferentes formas de significados construídos pelos grupos.

Essa diferença apontada por Street em relação a dois pensamentos em torno do letramento manifesta-se justamente por um fator de desigualdade social em torno do indivíduo. Se o modelo autônomo requer uma avaliação de acordo com os níveis de habilidades em torno do conhecimento das funções e dos níveis do texto de forma individual, como o sistema de ensino propõe, a ideia de pensar um modelo ideológico de letramento consiste em considerar que todos os indivíduos são "letrados", ou seja, possuem letramentos específicos, de acordo com sua cultura e com o território a que pertencem. Tendo em vista essa maneira de pensar um novo modelo de letramento, cabem reflexões que nos levam a meditar sobre uma nova forma de ensino e sobre as diversas práticas de leitura e escrita que se inserem em condições específicas.

\section{Alagoas e o contexto social quanto à realidade do campo}

A Educação no Campo, no Brasil, é apontada por diversos autores, como Calazans (1993), Leite (1999), Peludo (2001), Caldart (2004) e Arroyo (2007), dentre outros, de certa forma, relegada ao abandono pelo poder público. Estes autores são unânimes em retratar a Educação no Campo, em diversos períodos históricos, como sendo aquela pensada sob o paradigma urbano para a lógica urbana. Ou seja, não havia, até finais do século XX, 
propostas organizacionais de educação que percebesse as peculiaridades dos homens e mulheres do campo.

Para Arroyo (2007), o campo passou a ser visto como local do atraso, que precisaria ser resgatado em sua cultura. A educação, sob esse prisma, é a urbana, que tem como propósito resgatar os pobres do campo de sua condição. As políticas públicas, por esse tipo de visão, partiriam do paradigma urbano para inspirar o direito à educação. Mesmo não sendo esquecidas, as populações do campo seriam lembradas como as que necessitariam de adaptações das políticas educacionais urbanas às condições rurais. Nesse sentido, não haveria, propriamente, uma política educacional voltada para os saberes dos atores e atrizes do campo, mas para a acomodação e adaptação, ou, até mesmo, para uma continuidade das escolas urbanas.

As educadoras e educadores do campo, na verdade, seriam os mesmos, formados com os paradigmas urbanos que, em maior ou menor medida, deveriam adaptar as atividades pedagógicas à realidade do campo, mesmo que, durante sua formação, não tenham recebido aprofundamento nas áreas que iriam atuar. Acredita Martins (2001) que, no meio urbano, ocorre um processo de aculturação forçada, em que a sua referência seria a cultura urbana, "mais ficção do ideário urbano do professor e da política educacional do que expressão da realidade urbana em que o aluno vive" (MARTINS, 2001, p. 9). Ou seja, ocorreriam adaptações forçadas, tanto a partir do ideário urbano da formação das educadoras e educadores como da própria realidade urbana, que estaria desvinculada da formação de seus educandos.

Para o autor, o mesmo descompasso acontece no campo e, talvez, de modo agravado, em consequência de uma ideologia educacional que desvaloriza o mundo rural e o trabalho compesino. A ideologia do educador, no campo, costuma ser, via de regra, a ideologia que considera a cultura, os costumes, o saber da população que ele quer educar como cultura primitiva de povos ignorantes, consideradas formas incivilizadas de conhecer a vida e interpretar o mundo. Não raro, o educador é o grande responsável por abrir um amplo abismo cultural entre as gerações do mundo rural (MARTINS, 2001, p. 9).

Esta prática educativa não seria novidade nos sistemas de ensino. A lógica dissociada entre a educação urbana e a rural estaria na visão de que os homens e mulheres do campo não necessitariam de formação apropriada à sua realidade, tendo em vista que os conhecimentos que deveriam ser 
adquiridos deveriam focar, exclusivamente, o trabalho no campo que iriam realizar. Ou seja, ao mesmo tempo em que a educação passa a ser considerada como prioritária nas cidades, com o advento do processo de industrialização, a educação campesina deveria permanecer aquém dessa realidade. Ou seja, clamava-se "por uma educação de sentido prático e utilitário, e insistia-se na necessidade de escolas adaptadas à vida rural" (CALAZANS, 1993, p. 17).

Ao fazer uma reflexão, do ponto de vista ideológico dessas concepções, em maior ou menor medida, demonstravam a idealização da vivência no campo, desprovida do caráter integrativo entre campo e cidade. Para Calazans (1993) e Leite (1999), o êxodo rural, ocorrido no Brasil, especialmente a partir da década de 1930, desencadearia uma visão romantizada do campo, como local privilegiado de manutenção da vida, ou seja, manter o campo intacto, sem interferências urbanas, seria a forma de preservar a identidade dos homens e mulheres. A suposta felicidade que o homem adquiriria no campo, para Antônio e Lucinni (2007), ainda faria parte do ideário atual quando se pretende ampliar a educação no campo.

\footnotetext{
O entendimento comumente realizado parece estar sedimentado na concepção de educação rural, como aquela que, além de ensinar a ler, contar e escrever pode incluir técnicas agrícolas em seu currículo e assim estará contribuindo para fixar o homem no campo (ANTONIO; LUCINNI, 2007, p.3).
}

Esta situação necessita ser ampliada, procurando demonstrar a dinamicidade do campo e diversidades de fatores que são impulsionados e impulsionam a sociedade brasileira que vive no campo. Sendo assim, a educação rural deveria perder o qualificativo rural, para ser apenas educação. E educação do diálogo, educação na diversidade cultural, nas peculiaridades sociais, e não só em relação ao trabalho propriamente dito.

A educação deveria ser pensada como ponte de acesso à complexidade da sociedade moderna, que vem se tornando, também, social, cultural e politicamente, e até economicamente, a sociedade da diferença, da diversidade. O campo deixou de ser o mundo de diferentes e do direito à diferença, direito proclamado pelo sociólogo e filósofo francês Henri Lefebvre (MARTINS, 2001, p. 9).

O olhar diverso e plural ao homem do campo implica dizermos que não é necessário destituir a lógica urbana para construir a do campo, mas entender as peculiaridades de cada uma e as interconexões existentes, 
percebendo que "são dois espaços que possuem lógicas e tempo próprios de produção cultural, ambos com seus valores” (MEC, 2003, p. 32).

Especificamente, em Alagoas, a Educação do campo estende-se a um território com área de $27.767,661 \mathrm{~km}^{2}$, distribuída em 102 municípios, tendo como capital a cidade de Maceió. O estado é oficialmente subdividido em três mesorregiões (leste, agreste e sertão alagoanos).

Com a Lei no 5.692/71, de Diretrizes e Bases da Educação Nacional, o homem e a mulher do meio rural continuam sendo invisibilizados em sua realidade sócio-cultural, e as exigências reais da lei não inseriram o processo de formação escolar rural como uma política educacional específica.

Segundo o documento normativo do Parecer de Educação do campo do Estado de Alagoas (Parecer CEE/AL, 2014), nos últimos anos, tem ocorrido a falência de algumas usinas, maior fonte de renda do Estado, devido, em parte, à baixa produtividade da monocultura canavieira e a problemas climáticos de falta de chuva, e também, principalmente, à mundialização da economia, à transnacionalização do capital e à mecanização da agroindústria em outras regiões do país, que têm interferido na qualidade de vida dos povos do campo.

Somados a esse quadro, a falta de pesquisa no campo, de implantação de outras fontes alternativas de geração de renda, de trabalho digno, de emprego de recursos tecnológicos, geraram a indigência social em todas as regiões geográficas do Estado e aceleraram a expulsão do homem e da mulher do campo para as grandes cidades.

Em todo o Estado de Alagoas, o latifúndio dificulta a manutenção da população no campo, tornando o trabalhador rural, por falta da posse da terra, um trabalhador alugado, ou de meia, ou arrendatário de uma safra, ou simplesmente diarista, o que não deixa de ser uma forma de subemprego e semiescravidão, visto que, na maioria das vezes, este trabalhador recebe um salário extremamente precário, além de ter que atuar em baixas condições de sobrevivência.

Com essa realidade não há uma seguridade em relação aos direitos sociais de trabalho e, como consequência, os indicadores sociais no campo cada vez mais são os piores, pois acarretam alta de mortalidade infantil e baixos indicadores educacionais, no tocante ao ingresso e oportunidade de escolarização, a exemplo do analfabetismo, evasão, repetência, distorção idade e série que nos têm acompanhado por todos esses anos. 
A pressão do latifúndio e a falta de recursos naturais inviabilizam a sucessão rural e fortalecem o êxodo no campo: por falta de políticas públicas para os jovens rurais, acarreta-se o esvaziamento no campo e do trabalho na produção agrícola, somado ao descaso e à omissão dos governos municipais, estaduais.

Diante desse cenário, há quatro décadas que os movimentos do campo se organizam para reivindicarem direitos para os povos do campo e, em Alagoas, são diversas as organizações que resistem e propõem projetos de assentamentos da reforma agrária, com o objetivo de proporcionar a produção de alimentos saudáveis, respeitando a cultura e buscando a garantia de direitos, como educação, saúde, lazer, trabalho entre outros.

Para atender ao princípio da descentralização, defendido pela lei, o ensino rural foi induzido à municipalização. Em Alagoas, segundo o Parecer (CEE/AL, 2014), o período de crescimento mais nítido de sua oferta escolar ocorreu a partir da ditadura militar, sob a égide da Lei 5.692/71, de cunho municipalizante, com maior integração produtiva da economia do Nordeste à nacional que demandava a modernização no campo.

A partir destas políticas públicas, o governo federal investiu na expansão da rede escolar, induzindo um processo de repasse de responsabilidade aos municípios, ainda tendo a instância estadual como coordenadora do sistema. Nas décadas de 1980/90, o governo federal passou a lidar diretamente com os municípios, financiando principalmente a construção de prédios escolares, através do FNDE - Fundo Nacional de Desenvolvimento do Ensino.

A luta dos movimentos sociais em Alagoas por terra e políticas de acesso à terra tem se intensificado. Os movimentos sociais que atuam no Estado são: o Movimento dos Trabalhadores Rurais Sem Terra (MST), Comissão Pastoral da Terra (CPT), Fundação dos Trabalhadores e Trabalhadoras na Agricultura do Estado de Alagoas (FETAG/AL), Movimento de Libertação dos Sem Terra (MLST). É através dessa luta que os movimentos empreendem conquistas no território, acesso a políticas públicas para a sustentabilidade e posse de terra na região, garantindo a sobrevivência e a permanência das famílias no campo, numa disputa contra a lógica hegemônica de esvaziamento e êxodo rural.

\section{Considerações finais}


O eixo "Letramento e Educação do campo", apresentado na fase formativa do programa Escola da Terra, foi trabalhado na perspectiva de contribuir para o fortalecimento da Educação do campo e suas contribuições históricas e culturais, de modo a favorecer o conhecimento linguístico e a desconstrução de um modelo hegemônico de ensino normativista que favorece a norma gramatical padrão, não valorizando as diversas manifestações de linguagens presentes nas mais variadas culturas e povos.

Abordamos a língua como prática social, atribuindo-lhe atuação que transcende a lógica dominante e está em constante relação com as concepções de letramentos sociais, sobretudo ao conceito de letramento ideológico, que favorece as práticas locais, garante afirmação das identidades e contribui para uma outra concepção de aprendizagem, de acordo com o modelo de desenvolvimento sustentável proposto pelos movimentos do campo que reivindicam uma educação voltada para o campo, com conteúdos e reflexões que fortaleçam o acesso e permanência dos estudantes em seu local, garantindo-lhes sentido de pertencimento ao que lhes foi dado em sua essência.

Nesta perspectiva, evocam-se discussões que privilegiem os saberes e as necessidades do campo, embasadas na conjuntura de troca de conhecimento, com o intuito de se avançar coletivamente numa formação de cor local, que auxilie na discussão da realidade campesina imediata e nas práticas das escolas multisseriadas, com proposição de atividades de intervenção dos professores.

Assim, compreendemos na formação de professores do campo que os processos formativos, sobretudo no ensino de língua e linguagem, devem contribuir para um olhar crítico sobre o ensino e para reflexões, por exemplo, sobre variação linguística e preconceitos decorrentes do uso regional da linguagem, no sentido de fortalecer a interdisciplinaridade e uma formação cada vez mais integral e integrada dos alunos.

Nesse caminho proposto pelo Programa Escola da Terra, é importante compreender que Educação do campo é mais que um conceito: trata-se de uma concepção política do papel do ensino e, nesse caso, as linguagens estão social e historicamente situadas no tempo e no espaço por um sujeito de vez e de voz.

Os resultados decorrentes das atividades práticas levantam desafios: talvez o maior deles reside na expansão do tempo das formações, 
considerado muito limitado para a grandeza de um Programa de natureza tão inclusiva, mediada, na maioria das vezes, pela escuta do aprendiz. Há também o fato de os professores, em sua maioria, trazerem para a sala de aula uma concepção de língua ainda firma em prescrições gramaticais e, como vimos, a desconstrução destes saberes tradicionais e que detêm em si relação de poderes, requer um período maior de práticas reflexivas: só assim formaremos cidadãos para o letramento e para a cidadania marcados pela identidade topográfica de cada estudante, seja ele campesino ou urbano.

Segundo a coordenação do programa Escola da Terra, embora as formações tenham auxiliado na consolidação dos objetivos da Educação no Campo, há também de se lamentas que a maior parte das escolas multisseriadas em Alagoas estão sendo fechadas, com a crise no setor sucroalcooleiro, visto que muitos fazendeiros estão optando pela agropecuária e, em decorrência disso, demolindo as casas e obrigando as famílias a um novo êxodo rural.

\section{Referências}

ARRoyo, M.G. Políticas de formação de educadores(as) do campo. Cad. CEDES [online]. 2007, vol.27, n.72, pp.157-176.

ACHARD, P. (1989). “Um ideal monolíngue”, In: G. VERMES e J. BOUTET (Org. ). Multilinguismo. Trad. de Celene Meire. Campinas: Editora da Unicamp.

BRASIL. Lei 5.692, de 11 de agosto de 1971. Fixa Diretrizes e Bases para o ensino de $1^{\circ}$ e $2^{\circ}$ graus, e dá outras providências. Brasília, DF: 1971.

CALDART, R. Sobre educação do campo. IN: SANTOS, Clarice Aparecida dos. Educação do campo. Campo - Políticas Públicas - Educação. Brasília: INCRA, 2008.

CALAZANS, Maria Julieta Costa. Para compreender a educação do Estado no meio rural. In: DAMASCENO, Maria n. \& THERRIEN, Jacques (Org.). Educação e escola no campo. Campinas, Papirus, 1993.

CÉSAR, A. L.; CAVALCANTI, M. C. (2007). Do singular para o multifacetado: $o$ conceito de língua como caleidoscópio.

LUCINI, M. A formação de professores do campo: necessidades e possibilidades. In: PINHEIRO, A.S. et al. (Org.). Educação, currículo, ensino e formação de professores. Francisco Beltrão: UNIOESTE, 2007. 
MARTINS, J.S. Educação rural e o desenraizamento do educador. Revista espaço acadêmico, no 49, junho 2001.

MARCUSCHI, Luiz Antônio. Produção de texto, análise de gêneros e compreensão. São Paulo: Parábola Editorial, 2008.

MIGNOLO, Walter, D. Desobediência epistêmica: a opção descolonial e o significado de identidade em política. Traduzido por: Ângela Lopes Norte. Cadernos de Letras da UFF - Dossiê: Literatura, língua e identidade, n. 34, 2008.

MOITA LOPES, Luiz P. 1996. Afinal o que é Linguística Aplicada? In: Luiz P. Moita Lopes. Org. Oficina de Linguística Aplicada. Campinas/SP: Mercado de Letras.

MOITA LOPES, Luiz P. Representação social e encaminhamento pedagógico da leitura na escola pública brasileira. Revista Letra, Rio de Janeiro, n.4, p. 137147, 1993.

PEPE, C.M. et all. Relatório Final do Projeto Escola da Terra em Alagoas. Biênio 2015/2016. Maceió/AL, 2016.

RAJAGOPALAN, K. Por uma linguística crítica: linguagem, identidade e a questão ética. São Paulo: Parábola editorial, 2003.

SANTOS, Sanádia Gama. Variação linguística e Educação do campo em Alagoas. Maceió/AL, 2017 (Em andamento).

Recebido em: 05/11/2017

Aprovado em: 04/12/2017 